\title{
News media coverage of euthanasia: a content analysis of Dutch national newspapers
}

\author{
Judith AC Rietjens ${ }^{1 *}$, Natasja JH Raijmakers ${ }^{1}$, Pauline SC Kouwenhoven ${ }^{2}$, Clive Seale ${ }^{3}$, Ghislaine JMW van Thiel ${ }^{2}$, \\ Margo Trappenburg ${ }^{4}$, Johannes JM van Delden ${ }^{2}$ and Agnes van der Heide ${ }^{1}$
}

\begin{abstract}
Background: The Netherlands is one of the few countries where euthanasia is legal under strict conditions. This study investigates whether Dutch newspaper articles use the term 'euthanasia' according to the legal definition and determines what arguments for and against euthanasia they contain.

Methods: We did an electronic search of seven Dutch national newspapers between January 2009 and May 2010 and conducted a content analysis.

Results: Of the 284 articles containing the term 'euthanasia', 24\% referred to practices outside the scope of the law, mostly relating to the forgoing of life-prolonging treatments and assistance in suicide by others than physicians. Of the articles with euthanasia as the main topic, 36\% described euthanasia in the context of a terminally ill patient, $24 \%$ for older persons, $16 \%$ for persons with dementia, and 9\% for persons with a psychiatric disorder. The most frequent arguments for euthanasia included the importance of self-determination and the fact that euthanasia contributes to a good death. The most frequent arguments opposing euthanasia were that suffering should instead be alleviated by better care, that providing euthanasia can be disturbing, and that society should protect the vulnerable.

Conclusions: Of the newspaper articles, 24\% uses the term 'euthanasia' for practices that are outside the scope of the euthanasia law. Typically, the more unusual cases are discussed. This might lead to misunderstandings between citizens and physicians. Despite the Dutch legalisation of euthanasia, the debate about its acceptability and boundaries is ongoing and both sides of the debate are clearly represented.
\end{abstract}

Keywords: Euthanasia, Media, Content analysis

\section{Background}

The role of medicine and society in addressing the needs of patients who suffer unbearably and who request for their life to be ended is frequently debated. In the Netherlands, euthanasia was a topic of debate for many decades, eventually resulting in the legal regulation of euthanasia and physician-assisted suicide [1]. In several other countries, comparable regulation is in place or is currently being debated. These developments often yield emotional responses, and have given euthanasia and other life-ending practices, such as assisted suicide, a prominent place in news reporting.

\footnotetext{
* Correspondence: j.rietjens@erasmusmc.nl

'Department of Public Health, Erasmus MC, PO Box 2040, Rotterdam 3000

CA, the Netherlands

Full list of author information is available at the end of the article
}

Dutch euthanasia law defines euthanasia as the intentional ending of a life by the administration of medication by a physician at the explicit request of a patient [1], a definition that has been broadly accepted and adopted in legal regulations in other countries and in research. It is possible, however, that some people, amongst whom may be patients and healthcare providers, have different understandings of what euthanasia involves, potentially confusing them as to what is available under Dutch law, and certainly confusing the ethical debate. A recent Dutch study showed for example that several citizens considered the use of palliative sedation and the ending of life of severely ill newborns to be euthanasia [2].

Many people are exposed to media coverage of end-of-life care issues and mass media is a powerful source of information for the public [3]. Studies have shown, for example, that

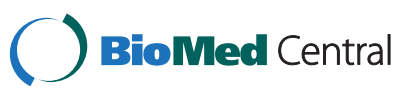


cancer news coverage influences the beliefs and behaviours of patients and healthcare providers $[4,5]$. It is, therefore, important to determine what practices are being referred to when newspaper reports label events as 'euthanasia', and to understand how news reporting represents arguments for or against the practice. Therefore, we studied reports about euthanasia in Dutch newspapers to investigate which practices the term 'euthanasia' refers to, and to study the content of these reports, in particular with respect to arguments for and against the use of euthanasia.

\section{Methods}

We conducted a content analysis of articles from seven nationwide Dutch newspapers. We selected newspapers because these media have been shown to be a primary source of trusted health information [6]. Our selection strategy was aimed at obtaining a balance between newspapers with a large circulation and newspapers with frequent reports about euthanasia. We also strived for variance in readership profiles, especially with respect to the educational level and the religious disposition of the readers, this latter traditionally being an important factor in Dutch society, reflected in the editorial orientation of some newspapers. We selected, therefore, the following newspapers: Nederlands Dagblad, Trouw, NRC, Volkskrant, $A D$, Telegraaf, and Spits!. These newspapers are circulated in hard copy as well as electronically.

Articles were identified through LexisNexis, a database which contains $98 \%$ of all Dutch newspaper articles. Our search period was January 2009 until May 2010. We selected those articles that contained the word "euthanasia" at least twice. We included regular news reports, letters to the editor, comments and features.
To ensure reliable coding, we developed, pretested and piloted a coding instrument, containing three stages. The first stage focussed on the use of the term euthanasia. Articles included in the sample were coded to determine whether the term euthanasia was used in accordance with the legal definition, and if not, to what other practice it referred. In the second stage, we first established whether euthanasia, according to the legal definition, was the main topic of the article or not. At this stage we also included articles in which the term euthanasia was used, but where there was no account of the practice to which it referred. The articles were coded to determine (1) whether they referred to specific patient groups, and if so, which; (2)

Table 1 Use of the term euthanasia in Dutch newspaper articles

\begin{tabular}{ll}
\hline & $\mathbf{n}=\mathbf{2 8 4} \%$ \\
\hline $\begin{array}{l}\text { The practice to which the term 'euthanasia' was } \\
\text { applied was described }\end{array}$ & $60(\mathrm{n}=170)$ \\
The term euthanasia was used for practices outside the & $24(\mathrm{n}=67)$ \\
scope of the euthanasia Law & \\
Where 'euthanasia' described practices outside the scope & \\
of Dutch euthanasia law it referred to: & $8(\mathrm{n}=24)$ \\
Forgoing life prolonging treatments & $5(\mathrm{n}=13)$ \\
Assistance in suicide by non-physicians & $4(\mathrm{n}=12)$ \\
Active ending of life without request of the patient & $2(\mathrm{n}=6)$ \\
Assistance in suicide by physicians & $1(\mathrm{n}=3)$ \\
Killing of animals & $1(\mathrm{n}=3)$ \\
Metaphor & $1(\mathrm{n}=2)$ \\
Ceasing eating and drinking & $1(\mathrm{n}=2)$ \\
Suicide & $1(\mathrm{n}=2)$ \\
Disproportionate increase of pain medication & \\
\hline
\end{tabular}


whether the message of the article was supported by numbers (indicating a fact-based rather than purely opinion piece); and (3) whether specific organisations or associations were used as sources of information, and if so, which. Finally, in the third stage, we assessed whether these articles contained one or more arguments for or against euthanasia, and we listed and classified the content of the arguments. See Figure 1 for a flowchart of the inclusion and coding process.

Each article was scored by two researchers (JR and NR) independently. Subsequently, the codes were compared and discussed when different. There were few differences in the scoring, and consensus was always reached readily.

\section{Results}

The search yielded 284 articles containing the term euthanasia at least twice (see Figure 1: Flowchart of sampling decisions).

In $60 \%$ of these articles $(n=170)$ the practice referred to by the term euthanasia was made clear (Table 1 ). In $24 \%$ of all articles $(n=67)$, the term euthanasia was used for practices outside the scope of Dutch euthanasia law, that is, not referring to the intentional ending of life by a physician at the explicit request of a patient. This concerned in most instances use of the term euthanasia

Table 2 Examples of use of the term 'euthanasia' for practices outside the scope of the euthanasia Law

\begin{tabular}{ll}
\hline Theme & Example \\
\hline Forgoing life prolonging & The euthanasia of Eluana Englaro in \\
treatments & Italy has led to much commotion. \\
& Premier Silvio Berlusconi tried two \\
& weeks ago at the very last minute to \\
& prevent the dehydration of the \\
& woman by submitting a provisional \\
& law. (De Telegraaf, 28-2-2009)
\end{tabular}

Active ending of life without request of the patient

Killing of animals

Metaphor for withholding or withdrawing potentially life-prolonging treatments ( $8 \%$ of all articles), for assisted suicide by physicians $(2 \%)$ or by others $(5 \%)$, and for active ending of life without an explicit request of the patient (4\%, such as ending of life of newborns). More rarely, the term euthanasia referred to the killing of animals, to the cessation of eating and drinking by a patient, to suicide, or to the disproportionate increase of pain medication without a patient request. In three articles, the term euthanasia was used as a metaphor: e.g. 'Facebook euthanasia' (the deletion of friends on Facebook) and 'workability euthanasia' (firing employees). See Table 2 for some examples.

In 134 of the 284 articles, euthanasia was the main topic. $68 \%$ of the 134 articles described the use of euthanasia for specific patient groups (Table 3). These concerned terminally ill patients in $36 \%$, older persons in $24 \%$, persons with dementia in $16 \%$, persons with a psychiatric disorder in $9 \%$, and persons in a coma in $5 \%$. Of 134 articles, $37 \%$ were supported by the use of numbers derived from reports of scientific research or opinion polls. Several articles cited opinions or statements from particular organizations. These included political parties, government ministries, medical professional organizations, 'Right to Die-NL' (a pro-euthanasia organization) and advisory or executive organizations (e.g. Dignitas in

Table 3 Characteristics of the newspaper articles

$\mathrm{N}=134 \%$

Persons $^{a}$

Terminally ill persons $\quad 36$

Older persons $\quad 24$

Persons with dementia $\quad 16$

Persons with a psychiatric disorder 9

Persons in a coma

Other persons $\quad 12$

Not specified $\quad 32$

Message of the article is supported by numbers 37

Organisations or associations used as sources ${ }^{a}$

Political parties 22

'Right to Die-NL', advisory or executive organisations 20

(Dignitas, Exit, De Einder)

Ministry/Public Prosecutor/Lower House $\quad 13$

Medical professional associations $\quad 13$

Support and Consultation for Euthanasia in the Netherlands 13 $(\mathrm{SCEN})^{b}$, Regional Review Committees for euthanasia

United Nations

11

Vatican, or other religious institutions 3

Patients' or older persons' associations 1

No organisations or associations cited

31

${ }^{\mathrm{a}}$ More than one possibility per article.

${ }^{b}$ Professional organisation that can be consulted for advise about euthanasia, one of the procedural requirements for legal euthanasia in the Netherlands. 
Switzerland). Patient organizations and religious institutions were mentioned less often.

Finally, those articles that contained one or more arguments for or against euthanasia were scrutinized (94 of the 134 articles, 70\%). See Figure 2 (Arguments for and against euthanasia in the Dutch newspapers) for a visual overview of the results, see Additional files 1 and 2 for a detailed account and see Tables 4 and 5 for some examples. Of these 94 articles, $67 \%$ contained at least one argument for euthanasia and $74 \%$ at least one argument against. Nearly half $(45 \%)$ of these articles contained arguments both for and against. The number of arguments for euthanasia ranged from 0 to 5 (mean: 1.33) and the number of arguments against from 0 to 7 (mean 1.72).

The most frequently mentioned argument for euthanasia referred to the desirability of self-determination by the patient $(40 \%)$ and to the contribution made by euthanasia to alleviating suffering (28\%). Other arguments in support of euthanasia were that it contributes to a good and dignified death (11\%), that people requesting euthanasia should not be abandoned (5\%), and that euthanasia prevents horrible suicides (5\%). The regulation of euthanasia was frequently referred to, predominantly claiming that regulation enhanced a careful and safe practice, and countering arguments against euthanasia suggesting it is a poorly practiced and difficult to regulate practice (20\%). In three articles, euthanasia was argued to be a potential solution for the aging of the population or a means to reduce medical costs.

Arguments against euthanasia also often referred to the suffering of patients, predominantly by arguing that suffering should be alleviated by better care rather than euthanasia (36\%). Further, it was argued that suffering can be meaningful in itself, and that suffering can mostly be prevented, for example by reducing overtreatment or resisting the excessive medicalisation of death, so that euthanasia would not be necessary (8\%). Other arguments against euthanasia were that it is disturbing for the physicians who carry it out (13\%) and that euthanasia is difficult to regulate (11\%). Societal or religious aspects were also referred to as arguments against euthanasia. The most mentioned arguments in these categories were that society should protect the vulnerable (11\%) and that human life in general should be protected (19\%). Finally, some articles contained the argument that it is impossible to prevent misuse of euthanasia given the fact that the formal review of each case required in the Dutch regulatory system takes place only after the deed has been done (4\%).

\begin{tabular}{|c|c|c|}
\hline & ARGUMENTS FOR EUTHANASIA & ARGUMENTS AGAINST EUTHANASIA \\
\hline $\begin{array}{l}\text { SELF- } \\
\text { DETERMINATION }\end{array}$ & Self-determination & $\begin{array}{l}\text { God disposes of life and death } \\
\text { How voluntary is a 'voluntary request'? }\end{array}$ \\
\hline SUFFERING/ DIGNITY & $\begin{array}{l}\text { Alleviates current suffering } \\
\text { Contributes to a good and dignified death } \\
\text { Do not abandon people (by denying euthanasia) } \\
\text { Prevents horrible suicides } \\
\text { Not all suffering can be alleviated by other means } \\
\text { Prevents future suffering } \\
\text { Prevents medicalisation of dving }\end{array}$ & $\begin{array}{l}\text { Suffering should be alleviated by better care } \\
\text { Suffering should be prevented } \\
\text { Suffering can be meaningful } \\
\text { Suffering is subjective and difficult to measure } \\
\text { Abrupt death (euthanasia) is an awful way of dying for patient or relatives } \\
\text { Suffering can pass } \\
\text { Unclear whether future suffering (as a reason for euthanasia) will occur }\end{array}$ \\
\hline $\begin{array}{l}\text { REGULATION / } \\
\text { PRACTICE / } \\
\text { RESPONSIBILITIES }\end{array}$ & $\begin{array}{l}\text { Regulation enhances carefulness } \\
\text { It happens anyway so it might as well be regulated } \\
\text { According to the law, people have aright to euthanasia }\end{array}$ & $\begin{array}{l}\text { Performance of euthanasia disturbing for the physician } \\
\text { It is difficult to regulate } \\
\text { A physician should never decide about someone else's quality of life } \\
\text { It is outside the scope of physicians' responsibilities } \\
\text { It is a poorly performed practice } \\
\text { It is outside the scope of normal medical practice } \\
\text { Suicide (without physician involvement) is better }\end{array}$ \\
\hline SOCIETY & $\begin{array}{l}\text { Solution for aging of the population/scarcity of resources / costs } \\
\text { It is a marker of a civilized society } \\
\text { It is what the majority of the society wants (democracy) }\end{array}$ & $\begin{array}{l}\text { Society should protect the vulnerable } \\
\text { Social pressure on older or sick persons burdens them with an 'option' } \\
\text { Too individual an approach, no attention for broader context } \\
\text { The personal wish to reach a good death should not be made political }\end{array}$ \\
\hline NON-INTERFERENCE & & $\begin{array}{l}\text { Human life in general should be preserved } \\
\text { A natural death is better than a non-natural death } \\
\text { Sign of disrespect for disabled people } \\
\text { It is murder }\end{array}$ \\
\hline $\begin{array}{l}\text { UNDESIRABLE } \\
\text { CONSEQUENCES }\end{array}$ & & $\begin{array}{l}\text { Euthanasia is final, there is no way back } \\
\text { Impossible to prevent misuse when review takes place after performance } \\
\text { Provokes impulse decisions by patients } \\
\text { Leads eventually to less attention for palliative care }\end{array}$ \\
\hline
\end{tabular}




\section{Table 4 Examples of arguments for euthanasia in Dutch newspaper articles}

\begin{tabular}{|c|c|}
\hline Theme & Example \\
\hline Self-determination, patient right & $\begin{array}{l}\text { The Royal Dutch Medical Association thinks that "euthanasia is neither a right of the patient nor } \\
\text { the duty of the physician". This is wrong. euthanasia should be a patient's right. Yes, the desire } \\
\text { to end life is subjective and therefore only the person him or herself can say whether it is the } \\
\text { right thing. It is ridiculous that the government believes that we are too immature, too } \\
\text { insignificant to make decisions about our lives ourselves. Shame. (letter, Trouw, 13-6-2009) }\end{array}$ \\
\hline Contributes to a good and dignified death & $\begin{array}{l}\text { Of course it is very emotional. I think that I did not sleep at all, each night following a } \\
\text { euthanasia case. But on the other hand, the serenity, the stateliness almost that nearly always } \\
\text { emerges when there is complete acceptance of death, is also very beautiful. What I learned from } \\
\text { this is that dying is not terrible. Saying goodbye: that's terrible. (Trouw, 9-1-2010) }\end{array}$ \\
\hline Regulation enhances carefulness & $\begin{array}{l}\text { The Euthanasia Act, Anne-Mei The concludes, was passed in order to protect society against } \\
\text { unwanted euthanasia practices. The benefit to the doctor is that he knows where he stands. } \\
\text { (Trouw, 28-11-2009) }\end{array}$ \\
\hline $\begin{array}{l}\text { Solution for aging of the population/ } \\
\text { scarcity of resources / medical costs }\end{array}$ & $\begin{array}{l}\text { If there are no taboos any more for possible financial cuts, give everyone from e.g. } 80 \text { or } 85 \\
\text { years the right to euthanasia. The advantages are clear, the government needs to pay less old- } \\
\text { age pension, the pension funds will for obvious reasons also be happy, and health insurers do } \\
\text { not need to spend fortunes to aim for a final age of } 120 . \text { I think there are many older people } \\
\text { who would make use of this. It is possible that this would yield more than } 4 \text { billion per year. So } \\
\text { let the state pension age just remain at 65. (letter, de Volkskrant, 19-09-2009) }\end{array}$ \\
\hline
\end{tabular}

\section{Table 5 Examples of arguments against euthanasia in Dutch newspaper articles}

Theme
care

Suffering can be meaningful; A natural death is better than a non-natural death

Society should protect the vulnerable; Human life should be preserved

Performance of euthanasia is disturbing for the physician

Performance of euthanasia is disturbing for the physician; It is outside the scope of normal medical practice; Abrupt death (euthanasia) is an awful way of dying for relatives

Example

Amyotrophic lateral sclerosis (ALS) is an incurable disease where adults increasingly have difficulties using their muscles. One in five ALS patients die by euthanasia in the Netherlands, while the overall euthanasia rate is only 1.8. [...] Foreign doctors have found this rate unacceptably high and have questioned the quality of care for ALS patients in the Netherlands. Theay have also wondered whether Dutch doctors perhaps undertreat depression and related death wishes in ALS patients. (Nederlands Dagblad, 11-9-2009)

The achievements of medicine are in many ways a blessing. The burden of pain, dyspnea and dehydration on the deathbed can be alleviated with palliative care and palliative sedation. (Trouw, 20-2-2010)

Each of us has probably once experienced someone in the immediate environment who was dependent on us. This is not a purely negative experience. The physical proximity allows for intimacy and the relationship thereby becomes deeper. Let us cherish the memory of such experiences. It is possible that this reduces the need to control dying. It can help us in taking a relaxed view at the end of life. Just like chips and a plate of hot food, a death that is normal probably tastes best. (Trouw, 20-2-2010)

[The Human Rights Commission of the United Nations] is most concerned, however, about Dutch euthanasia policy. Do vulnerable groups such as older people and the disabled not deserve to be better protected? [...] The UN Committee defends the widely shared view that life is too precious to be terminated. Moreover, they correctly point to the fact that social perceptions of old age and frailty can also be influential. Where dependence is linked to dehumanization and indignity, the 'art of dying well' (the true meaning of euthanasia) disappears. (Nederlands Dagblad, 18-7-2009)

Doctors are there to deal with medical affairs. They are there to keep people alive and to help them die in case of severe illness. But performing euthanasia is for almost every doctor highly personally invasive and stressful. (Volkskrant 20-3-2010)

The book (JR: "Verlossers Naast God" / Saviours besides God, by Anne Mei The) pains us, because it painfully shows what an enormous impact euthanasia can have on a doctor. 'My kids run to me and embrace me. I am fighting back my tears" is the last sentence of a doctor who comes home after he has "helped" a man. Doctors do not want to disappoint patients who trust them. But a request for euthanasia is not normal, just as the act itself is not. Even relatives are often shocked at their own reactions. Discontent among the "silent majority" of doctors began in 2001. The compassionate help provided in the past was exchanged for an abrupt action that goes against everything a doctor normally represents. (Nederlands Dagblad 2-12-2009) 


\section{Discussion}

The legalisation of euthanasia and physician-assisted suicide in the Netherland is considered by many to be a social experiment [7], and people in many other countries keep a (sometimes critical) eye on Dutch practices and debates [8]. While several studies have provided reliable estimates about the frequency and characteristics of the practice of euthanasia in the Netherlands [9], this is the first study providing an overview of how euthanasia is described and debated in Dutch newspapers. Our study shows that nearly a quarter of Dutch newspaper articles used the term euthanasia for practices that were outside the scope of Dutch euthanasia law. Further, our analysis showed the wide-ranging nature of the public debate. Euthanasia was discussed in varying contexts and situations: for terminally ill patients but even more so for other groups such as older persons, persons with dementia, or persons with a psychiatric disorder. Also, there was a large variety of organisations and associations used as sources as well as there being variety in the arguments for or against euthanasia.

The term euthanasia, literally meaning a "good death", has had different meanings depending on the historical and political context. Nowadays, euthanasia is understood by authorities to be the intentional ending of life by the administration of drugs by a physician at the explicit request of a patient[1], This definition is broadly accepted and adopted in legal regulations and in research. Yet nearly a quarter of the newspaper articles used the term euthanasia for practices that are outside the scope of this definition. In several instances, the term euthanasia referred to physician-assisted suicide (where the patient and not the physician administers the lethal drug), a practice that provokes quite similar moral debates as euthanasia, but is a different practice [1]. In other instances, the term euthanasia referred to practices that involve moral considerations that are different from those associated with euthanasia, such as the ending of life without a request of the patient (morally more problematic than euthanasia, many would feel) or the forgoing of potentially life prolonging treatments (usually morally less problematic, most would say). Also, the term was sometimes used for practices that do not involve a physician, including for example assisted suicide by non-physicians, suicide, or metaphorical usages. Taken together with the fact that $40 \%$ of the newspaper articles did not give any description of what practices the term euthanasia referred to, this means that one should be very cautious as to what people mean when they think they are discussing 'euthanasia'. Because newspapers are generally considered to be an important source of health information [6], this kind of definitional variability is likely to feed misunderstanding and confusion in public debates. Moreover, for effective public health policy and compliance with Dutch legal regulations, a shared understanding of key concepts and terminology is essential.

In 2010, of all deaths in the Netherlands, $2.8 \%$ were the result of euthanasia [9]. Physician-assisted suicide was practiced less often, in $0.1 \%$ of all deaths. The large majority of euthanasia patients were diagnosed with cancer, were younger than 80 years of age, had a very short life expectancy and all were considered to be mentally competent when they made their request [9]. Euthanasia for persons who are old but not terminally ill, or who have (partly) lost mental capacity (e.g. due to a psychiatric disease, a coma or dementia) is practiced rarely. Yet euthanasia for these patients groups is quite commonly discussed in Dutch newspaper articles. Rather than reflecting practice, this reflects current medical and political debates about euthanasia which predominantly focus on the boundaries of current legislation. Examples of such boundary debates include the legitimacy of accepting "unbearable suffering" as a reason for euthanasia in patients with no serious medical condition $[10,11]$, and the degree to which advance directives might substitute for a verbal request when the patient has become mentally incapacitated [12-14]. Media coverage of the practice of euthanasia, therefore, reflects a focus on more controversial cases rather than reporting on the majority of situations in which euthanasia is actually performed. While the media as such fulfils an important task of contributing to a societal debate and highlighting controversy, such coverage may lead to an inaccurate perception of the practice of euthanasia by the public [15].

Until recently, the Netherlands was known for tolerant policies on controversial issues such as abortion, drug abuse and euthanasia [16]. Factors often mentioned as contributing to these policies are the openness of the Dutch in discussing difficult issues, their tendency to prefer consensus and a strong trust in health-care providers $[8,17]$. This is also reflected in the fact that the Euthanasia Law receives ample support among the general public and health care professionals [18]. However, our study shows that Dutch public debate about euthanasia, especially its boundaries, does not necessarily involve an easy consensus. The opinions of both advocates and opponents allowing euthanasia for controversial groups are clearly visible, with a wide array of arguments for and against euthanasia being presented. The most commonly used arguments for euthanasia were that selfdetermination is a right and that the practice alleviates severe or unbearable suffering. The responsibility of society to regulate the response to the wish for assistance in dying of patients experiencing unbearable suffering was emphasised in these arguments, which are all central in current medical, ethical and political debates about 
euthanasia. A few newspaper articles argued that euthanasia might be a solution for the aging of the population or be a way of conserving scarce resources, which is obviously a morally more problematic argument, though perhaps attractive to journalists wanting to focus on more extreme positions. Arguments against the use of euthanasia refuted the right to self-determination and presented a different perspective on the core responsibilities of society, by focussing on the need to protect the vulnerable. There were also claims that suffering can be meaningful.

Our study also sheds light on a less debated aspect of the practice of euthanasia, that is, whether euthanasia contributes to a good death. This argument divides opponents and advocates of euthanasia. On the one hand, it is argued that euthanasia might contribute to a good, dignified, "civilized" death, for example by preventing distressing forms of suicide. On the other hand, euthanasia is described by some as too abrupt and unnatural for both patients and relatives and as a disturbing experience for physicians. This illustrates how perceptions about this practice and the dying phase in general may vary, and it underlines the need for medical practitioners to both counsel patients and their families about the course of their illness and dying phase, and to consider their own responses to such momentous end-of-life decisions as euthanasia.

\section{Conclusions}

Nearly a quarter of the newspaper articles use the term euthanasia for practices that are outside the scope of Dutch euthanasia law, and newspapers typically discuss the more unusual cases such as euthanasia for patients with dementia or a psychiatric disorder. This has the potential to confuse the public debate about euthanasia, and means that physicians should be aware that their patients may have mistaken views about what euthanasia is, who it is for, and what circumstances lead to a decision to carry out euthanasia. Despite the legalisation of euthanasia in the Netherlands, the debate about its acceptability and boundaries is ongoing and both sides of the debate are clearly represented.

\section{Additional files}

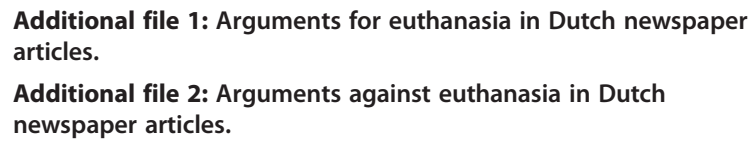

Competing interests

The authors declare that they have no competing interests.

\section{Authors' contributions}

JACR and NJHR were responsible for the analysis of the data. All authors made substantial contributions to conception and design of the work, acquisition of data, or analysis and interpretation of data; drafting the article or revising it critically for important intellectual content; and final approval of the version to be published.

\section{Author details}

'Department of Public Health, Erasmus MC, PO Box 2040, Rotterdam 3000 CA, the Netherlands. ${ }^{2} J$ ulius Center, University Medical Center Utrecht, the Netherlands Huispost Str 6.131, postbus 855003508 GA, Utrecht, the Netherlands. ${ }^{3}$ Department of Sociology and Communications, Brunel University, Uxbridge, Middlesex UB8 3PH, UK. ${ }^{4}$ Utrecht School of Governance, University of Utrecht, Bijlhouwerstraat 6, Utrecht 3511 ZC, the Netherlands.

Received: 2 November 2012 Accepted: 27 February 2013

Published: 6 March 2013

\section{References}

1. Janssen A: The new regulation of voluntary euthanasia and medically assisted suicide in the Netherlands. Int J Law Policy Family 2002, 16(2):260-269.

2. van Delden JJM, Van der Heide A, van de Vathorst S, Weyers H, van Tol DG: Kennis en opvattingen van publiek en professionals over medische besluitvorming en behandeling aan rond het einde van het leven. Het KOPPEL onderzoek. (Knowledge and attitudes of the public and professionals about medical decision-making and treatments at the end of life. The KOPPEL study. Den Haag: ZonMw; 2011.

3. Nelkin D: Selling science: How the press covers science and technology. New York: WH Freeman Co; 1995.

4. Nattinger AB, Hoffmann RG, Howell-Pelz A, Goodwin JS: Effect of Nancy Reagan's mastectomy on choice of surgery for breast cancer by US women. JAMA 1998, 279(10):762-766.

5. Yanovitzky I, Blitz CL: Effect of media coverage and physician advice on utilization of breast cancer screening by women 40 years and older. $J$ Health Commun 2000, 5(2):117-134.

6. Niederdeppe J, Hornik RC, Kelly BJ, Frosch DL, Romantan A, Stevens RS, Barg FK, Weiner JL, Schwartz JS: Examining the dimensions of cancer-related information seeking and scanning behavior. Health Commun 2007, 22(2):153-167.

7. Gillon R: Euthanasia in the Netherlands-down the slippery slope? J Med Ethics 1999, 25(1):3-4.

8. Cohen-Almagor R: Why the Netherlands? J Law Med Ethics 2002, 30(1):95-104.

9. Onwuteaka-Philipsen BD, Brinkman-Stoppelenburg A, Penning C, de Jong Krul GJ, van Delden JJ, van der Heide A: Trends in end-of-life practices before and after the enactment of the euthanasia law in the netherlands from 1990 to 2010: a repeated cross-sectional survey. Lancet 1990, 380(9845):908-915.

10. Pasman HR, Rurup ML, Willems DL, Onwuteaka-Philipsen BD: Concept of unbearable suffering in context of ungranted requests for euthanasia: qualitative interviews with patients and physicians. BMJ 2009, 339:b4362.

11. Rietjens JA, van Tol DG, Schermer M, van der Heide A: Judgement of suffering in the case of a euthanasia request in the Netherlands. J Med Ethics 2009, 35(8):502-507.

12. de Boer ME, Droes RM, Jonker C, Eefsting JA, Hertogh CM: Advance directives for euthanasia in dementia: how do they affect resident care in dutch nursing homes? experiences of physicians and relatives. J Am Geriatr Soc 2011, 59(6):989-996.

13. de Boer ME, Hertogh CM, Droes RM, Jonker C, Eefsting JA: Advance directives in dementia: issues of validity and effectiveness. Int Psychogeriatr 2010, 22(2):201-208.

14. de Boer ME, Droes RM, Jonker C, Eefsting JA, Hertogh CM: Advance directives for euthanasia in dementia: do law-based opportunities lead to more euthanasia? Health Policy 2010, 98(2-3):256-262.

15. Seale C: Media \& health. London: SAGE Publications Inc; 2002.

16. van der Maas PJ, Pijnenborg $L$, van Delden JJ: Changes in dutch opinions on active euthanasia, 1966 through 1991. JAMA 1995, 273(18):1411-1414

17. Kennedy J: A well-considered death [In dutch: een weloverwogen dood]. Amsterdam: Prometheus Groep; 2002.

18. Kouwenhoven PS, Raijmakers NJ, Delden JJ, Rietjens J, Schermer MH, van Thiel GJ, Trappenburg M, van de Vathorst S, van der Vegt B, Vezzoni C, et al: Opinions of health care professionals and the public after eight years of euthanasia legislation in the netherlands: a mixed method approach. Palliat Med 2012. doi:10.1177/0269216312448507. E-pub ahead of print; published online 13 June 2012.

doi:10.1186/1472-6939-14-11

Cite this article as: Rietjens et al.: News media coverage of euthanasia: a content analysis of Dutch national newspapers. BMC Medical Ethics 2013 $14: 11$. 